\title{
RESGATE DA MEMÓRIA EM CÂNDIDO PORTINARI
}

Emília Vicente Lourenço ${ }^{1}$

\section{Resumo}

O presente trabalho, fragmento da pesquisa em desenvolvimento no Programa de Pósgraduação do Instituto de Artes da Universidade de Brasília, tem como objetivo analisar o fenômeno da memória dentro do campo antropológico. Para tanto, foi utilizado como aporte pictórico o projeto em cartão para mosaico da obra "Jesus e os Apóstolos", de Cândido Portinari. O objetivo norteador do trabalho é o estudo da lacuna existente entre o projeto e o mosaico, que não chegou a ser realizado, e o resgate da "memória de esquecimento", correspondido entre os anos de 1958 e 2003. A questão da simbologia presente na obra também é levada em consideração através de uma análise formal da iconologia central da obra, que faz parte de uma memória comum e cujo icograma é representado desde o período paleocristão.

Palavras-chave: memória de esquecimento, memória coletiva, mosaico.

O presente trabalho, fragmento da pesquisa em desenvolvimento no Programa de Pós-graduação do Instituto de Artes da Universidade de Brasília, tem como objetivo analisar o fenômeno da memória dentro do campo antropológico em suas diversas subdivisões. Para tanto, foi utilizado como aporte pictórico o projeto em cartão para mosaico da obra "Jesus e os Apóstolos”, de Cândido Portinari (1903-1962).

O objetivo norteador do trabalho é o estudo da lacuna existente entre o projeto e o mosaico, que não chegou a ser realizado, e o resgate da "memória de esquecimento", consolidado por Maurice Halbwachs em 1925, e que é correspondido entre os anos de 1958 e 2003, período em que qualquer informação referente à execução do projeto de "Jesus e os Apóstolos" ficou longe do conhecimento público, não sendo divulgada por nenhum meio de comunicação.

A questão da simbologia presente na obra também é levada em consideração através de uma análise formal da iconologia central da obra, que faz parte de uma memória comum e cujo icograma é representado desde o período paleocristão.

O projeto de "Jesus e os Apóstolos" consta de três estudos feitos a grafite e lápis de cor/papel, sendo que suas medidas são $20 \times 46 \mathrm{~cm} ; 19,5 \times 46,5 \mathrm{~cm}$ e $32,5 \times 48 \mathrm{~cm}$, e foram realizados por Cândido Portinari em 1957, atendendo a Oscar Niemeyer que o convidou a integrar a equipe da construção da nova capital com uma obra que fosse disposta na Capela do Palácio da Alvorada, residência do presidente da república. O projeto, porém, não chegou a ser executado, e ainda hoje os reais motivos para a não realização da obra permanecem desconhecidos.

O que há é um contraponto entre memória ausente, devido à falta de um discurso oficial, não fosse a retomada em função do centenário de nascimento do artista, e uma memória presente em relação às críticas a Portinari, provindas principalmente de artistas do projeto construtivista que, segundo Frederico Morais (1975: 81), consideravam que "o extraordinário prestígio e sucesso do artista na área oficial estavam retardando o

\footnotetext{
${ }^{1}$ Mestranda do Instituto de Artes da Universidade de Brasília na área de concentração Teoria e História da Arte, sob orientação da professora Dra. Grace de Freitas; bolsista Capes. Graduada em Artes Plásticas pela Universidade Federal de Uberlândia (2003) onde desenvolveu Projeto de Iniciação Científica PIBIC/CNPq com trabalhos sobre Cândido Portinari sob orientação da professora Dra. Yacy Ara Froner.
} 
desenvolvimento da arte brasileira", o mesmo autor explana ainda que "influenciada pelo muralismo mexicano e pelo expressionismo internacional, impunham, via Portinari, uma visão deformada de nossa realidade social".

O discurso de uma memória excludente, construído na década de 60 , é que sustenta o pensamento e aponta para a resposta para a inexistência do mosaico.

O projeto de "Jesus e os Apóstolos" apresenta Jesus no centro geométrico do cartão com os doze apóstolos divididos em dois grupos, sendo cada grupo em uma extremidade, e mostrados em posição de adoração.

A imagem faz parte de uma representação comum, renitente e sem mais questionamentos acerca da simbologia por ser, desde o século IV, após inúmeras perseguições $^{2}$, freqüentemente representada, sendo que constam do século anterior as primeiras manifestações da pintura cristã.

Traços da pintura paleocristã, como "frontalidade, plenitude e desmaterialização das figuras, hieratismo, fuga do concreto e característico desinteresse pelo ambiente e pelo mundo sensível” (LOPERA, et al., 1995: 46) são visíveis no projeto da obra.

\section{Memória}

"Mnemosyne, mãe das musas, filha de Urano e Gaia. Mnemosyne e Lethe, memória e esquecimento, que funcionam como um par de forças complementares" (Coimbra, 1997: 13 e 15). Assim o autor inicia suas "Considerações acerca do tempo, da memória e do esquecimento", onde afirma que a relação entre memória e esquecimento, mesmo entre os pitagóricos e depois com Platão, passa a ser compreendida de uma outra forma, sendo que a primeira torna-se o meio pelo qual o homem pode escapar das garras do devir, do perecimento - da condição humana, enfim. E o esquecimento será justamente associado ao tempo.

"Memória coletiva", conceito abstraído de Maurice Halbwachs (1990: 81-82), caracteriza-se por se dar em um contexto social cujo melhor exemplo é a "memória nacional". Somos sujeitos históricos, portanto, a coletividade está presente não só na construção da identidade dessa coletividade, mas também no ato de recordar. Contudo, a "memória coletiva" se distingue da história pelo menos sob dois aspectos, é uma corrente de pensamento contínuo, de uma continuidade que nada tem de artificial, já que retém do passado somente aquilo que ainda está vivo ou capaz de viver na consciência de grupo, e, por outro lado, podemos dizer que sempre, uma construção do presente que se dá por meio das vivências ocorridas no passado, isso porque o homem, apesar de carregar em si as lembranças, está em constante interação com o meio em que vive.

Destarte, a memória é entendida como um fenômeno construído coletivamente e submetido a flutuações, transformações e mudanças constantes.

Halbwachs (1990: 51) assegura ainda que tendemos a considerar a memória como sendo exclusivamente individual, porém, cada memória individual é um ponto de vista sobre a "memória coletiva", e este ponto de vista muda de acordo com o lugar que ocupamos, e o lugar também muda segundo as relações que mantemos com outros meios.

\footnotetext{
2 A aprovação do cristianismo como religião pelo Imperador Constantino, no ano 313 depois de Cristo, só aconteceu após inúmeras outras perseguições, dentre elas, cumpre ressaltar a primeira, do Imperador Nero, ocorrida no ano 64 depois de Cristo. Porém, só no ano de 391 é que o cristianismo foi oficializado como religião.
} 
O período correspondido entre 1958 e 2003, denominado como "período de esquecimento", entendido ainda como uma lacuna no tempo entre o que existe - projeto em cartão - e o que não existe - mosaico -, foi causado pela história oficial, que é necessária para a construção da "memória social", formada através da sucessão de fatos e acontecimentos na sociedade.

A "memória de esquecimento", definida por Bérgson (apud Coimbra, 1997: 10) como sendo uma

memória-lacuna, ou de um esquecimento constitutivo, é algo da ordem do sintoma, ponto onde lembrança e esquecimento que se encontram e passam a responder por uma nova função: afirmar novas formas de atualização, vale dizer, de subjetivação.

Se, segundo Halbwachs (1990: 77), "não há na memória vazio absoluto, ao contrário, o passado permanece inteiramente dentro de nossa memória, tal como foi para nós", conclui-se que toda memória se refere a um fato, num espaço e num determinado tempo, deste modo, o que há são trocas recíprocas e constantes entre o indivíduo e a sociedade e, são essas trocas que constroem o contexto histórico.

Leva-se a pensar, desta forma, que o contexto não existe a priori, mas que ele é construído a partir da posição em que ocupa no mirante do aqui-agora, que se volta para trás, a partir das negociações com o passado por meio da memória. Assim sendo, a memória se manifesta no presente para responder às questões abertas do passado.

É salutar destacar o papel das narrativas, pois é através das histórias passadas e transmitidas pelos familiares, pela imprensa, por livros, e por outros meios, que se recebe os primeiros relatos de humanidade.

Halbwachs (1990: 56) afirma que cada sociedade recorta o espaço a seu modo, de tal forma a constituir um quadro fixo onde encerra e localiza suas lembranças, e quanto ao tempo, diz que os acontecimentos históricos não desempenham um outro papel senão as divisões do tempo assinaladas num relógio, ou determinado pelo calendário.

Deste modo, a linguagem, o tempo e o espaço são, para o autor acima referido, quadros sociais de memória, estes considerados mais importantes.

As narrativas dizem respeito a fatos contados a partir da seqüência que tem início, meio e fim, e que é permeada pela relação entre o narrador e o interlocutor, havendo assim, a partir desta relação, uma negociação constante de significados. Parte-se do princípio, por conseguinte, que o outro colabora para uma interatividade reflexiva.

Pode nos parecer estranho buscar informações de um mundo que não existe mais, mas precisamos, como sugerido por Darton (1986: 144), "para penetrar na consciência desse mundo que não mais existe, nos ater e concentrar mais nos modos de como foi escrita a história do que nos objetos escritos".

Campos (1992: 83 e 91) permite-nos uma terminação que se faz perfeita tendo-se em vista as colocações dos autores aqui utilizados ao falar da experiência da arte como uma experiência privilegiada de uma projeção de possíveis, sendo que o que se interpreta é uma abertura para realidades novas.

\section{O Projeto Portinari como guardião de uma memória}

O Projeto Portinari, por ser um guardião da memória, tanto da vida quanto da obra do artista, é importante aqui como suporte, principalmente por deter a grande maioria das informações do artista e por contribuir com o florescimento de suas memórias. 
Sob direção de João Cândido Portinari, filho único de Cândido Portinari, iniciou os trabalhos de busca e catalogação das obras do artista em 1979, e funciona ainda hoje juntamente à Pontifícia Universidade Católica do Rio de Janeiro, tendo como objetivo central, segundo Berardo (1983: 37), "cultuar a memória e as obras daquele que foi o maior artista brasileiro da América Latina”. Assim sendo, é de se considerar a importância deste, principalmente pela catalogação de inúmeras obras que se encontravam em coleções particulares, museus, instituições religiosas e muitas ainda desaparecidas.

Mesmo sendo interpretada como uma instituição de caráter elitista, por monopolizar a produção de Portinari, como afirma o autor supracitado, é de se considerar que o conhecimento das obras daquele artista, sobressalente em relação aos demais, de igual expressividade e participação cultural, se deve justamente ao trabalho desenvolvido pelo Projeto Portinari.

A memória resgatada se fez ao longo dos anos e alcançou o auge no ano de 2003, ano comemorativo do centenário de nascimento de Cândido Portinari. Exposições, lançamentos de livros, comerciais na televisão e até mesmo a disposição no mercado do Catálogo Raisonné, sendo Portinari o único artista latino americano a possuir toda a obra compilada em um único catálogo chegando a 2000 páginas.

Ainda hoje a memória e difusão sobre a vida e a obra do artista persistem através, principalmente, de exposições, não com tanto ímpeto como em 2003, mas mesmo assim é como uma memória que vem à tona. Contudo, não foi sempre assim, e a dominação sobre os materiais referentes ao artista, como correspondências, imagens e recortes de jornais permanecem sob estrito poder da direção do Projeto Portinari.

\section{O Centenário como projeção da memória do esquecimento}

Em 2003 comemorou-se o centenário de nascimento de Cândido Portinari, e, com isso, muitas questões foram retomadas. Isso leva-nos a compreender e também a questionar se a memória é seletiva apenas para o indivíduo ou, se no que se refere à sociedade, ela também apresenta características de seletividade.

Se pensarmos de acordo com Pollak (1992: 4), veremos que a memória é em parte herdada, não se referindo apenas à vida física da pessoa, ela também sofre flutuações em detrimento do momento em que está sendo articulada e expressa. Assim, a comemoração do centenário do nascimento de Cândido Portinari pode ser entendida como um elemento de estruturação e de projeção da memória. É, como prossegue o mesmo autor ao designar uma memória subterrânea, que "aflora em determinados momentos, em sobressaltos bruscos e exacerbados".

Necessário ainda, para uma melhor compreensão das questões entre a obra de Portinari e a memória, é a aplicação do termo "memória compartilhada", que para caracterizá-la Pollak (1992: 8-9) introduz o conceito de "trabalho de enquadramento" da memória. As formas de configuração dessa "memória compartilhada" podem ser entendidas através de componentes que alimentam o "trabalho de enquadramento".

Dentre esses componentes, a re-interpretação, re-elaboração e re-significação do material fornecido pela história, adquire especial significação dependendo do colorido da experiência do presente.

Outro componente se refere às formas de como as organizações sociais se valem do material fornecido pela história e re-interpretam seu passado, elaborando a imagem pela qual desejam ser lembrados. 
Ainda um componente, ao qual o trabalho se detém com mais afinco, é o papel reservado aos "lugares de memória", ou seja, pontos de referência de um "trabalho de enquadramento" que faz parte de um processo de seleção dos símbolos e rastros culturais ou históricos dos grupos sociais. Podem ser monumentos, museus, e, especificamente para este trabalho, a Capelinha do Palácio da Alvorada, ponto inicial de todo o processo de construção da memória acerca de "Jesus e os Apóstolos".

Por fim, há a propaganda, componente defendido por Pollak como sendo o melhor suporte para qualquer "trabalho de enquadramento", por oferecer a base necessária para o trabalho.

A Capelinha do Palácio da Alvorada, que seria depositária da obra, se constitui como importante fonte de identificação da "memória coletiva", por ser um lugar de representação, e mesmo não tendo concluído o projeto final do mosaico de Portinari, lá se encontram painéis de Athos Bulcão, e não deixa de ser com isso um "lugar de memória".

Freire (1997: 127) expõe que, apesar dos monumentos serem "lugares de memória", as elaborações referentes a eles reafirmam que a memória é antes de tudo um processo, uma construção dinâmica, passível de ser reelaborada constantemente diante das experiências vividas, e conclui que a memória não tem um conteúdo estático, capaz de ser "resgatado" invariavelmente.

Numa sociedade de "memórias coletivas", quando a sociedade se integra bem na memória nacional dominante, sua coexistência não coloca problemas, ao contrário das "memórias subterrâneas". Fora dos momentos de "crise" ou "efervescência", que pode ser entendido aqui como sendo a comemoração do centenário do nascimento de Portinari, estas últimas são difíceis de localizar e exigem que se recorra ao instrumento da história oral.

Indivíduos de certos grupos teimam em venerar justamente aquilo que os enquadradores de "memória coletiva", em um nível mais global, se esforçam por minimizar ou eliminar.

A análise do "trabalho de enquadramento" de seus agentes e de seus traços materiais é uma chave para estudar, de cima para baixo, como as "memórias coletivas" são construídas, desconstruídas e reconstruídas. Por outro lado, o procedimento inverso, aquele que, com os instrumentos da história oral, parte das memórias individuais, faz aparecerem os limites desse "trabalho de enquadramento" e, ao mesmo tempo, revela um trabalho psicológico do indivíduo que tende a controlar as feridas, as tensões e contradições entre imagem oficial do passado e suas lembranças pessoais.

O "trabalho da memória" é indissociável da organização social da vida, e, no "trabalho de enquadramento" da memória, o alimento de pesquisa é fornecido pela história, onde a referência ao passado serve para manter a coesão dos grupos e das instituições que compõem uma sociedade, como também para definir seu lugar respectivo, sua complementaridade, mas também oposições irredutíveis.

\section{Bibliografia}

BERARDO, João Batista. O político Cândido Torquato Portinari. São Paulo: Edições Populares, 1993.

CAMPOS, Maria José Rago. Arte e verdade. São Paulo: Loyola, 1992.

COIMBRA, José César. Freud, Lacan, Bergson, Foucaut - considerações acerca do tempo, da memória e do esquecimento. São Paulo: Cone Sul, 1997. 
DARTON, Robert. O grande massacre dos gatos. Rio de Janeiro: Graal, 1986.

FREIRE, Cristina. Além dos mapas - monumentos no imaginário urbano contemporâneo. São Paulo: FAPESP, 1997.

HALBWACHS, Maurice. A memória coletiva. São Paulo: Vértice, 1990.

LOPERA, José Alvarez. et al. História geral da arte. Espanha: Ed. Del Prado, Vol. I, 1996.

POLLAK, Michel. Memória e identidade social. Estudos Históricos, 2(3): 3-15 1998. 